\title{
From 1984 to Birch: The Politics of Cultural and Traditional Arts/Games in the Plays of Kee Thuan Chye
}

\author{
David Tneh
}

Malaysian playwright Kee Thuan Chye's plays such as 1984 Here and Now, The Big Purge and We Could **** You, Mr. Birch have always placed Malaysian politics as their centre stage discourse. ${ }^{\mathrm{i}}$ Through his plays, Kee provides an intimate glimpse of Malaysian politics and the individual who struggles to make meaning out of the drudgery of the power struggle between the state and the individual.

While Kee's focus, as Gilbert and Lo suggest in their Introduction to 1984 Here and Now, has been on how "existing hegemonic power structures perpetuate gross inequalities in the Malaysian society" (6), he has also touched on the social relations among races and communal groups that were discriminated against by race-based policies of the National Economic Policy (NEP).

This paper takes a deeper look at the meaning of cultural/traditional recreational activities depicted in three of Kee's political plays arguing that activities are not mere social activities but a manifestation of a deeper network of symbolisms and a manifestation of the politics of representation and dissent by Kee towards the hegemony of the political state.

\section{Kee Thuan Chye's Plays and Malaysian Politics}

Kee, as a Malaysian playwright is pushing for a distinct Malaysian drama with its own unique identity. Weaved into such portrayals of cultural activities and traditional games, are elements such as humour which is distinctly Malaysian in flavour, elements of sarcasm, parody of Malaysian politicians and political parties, and lamentations on corruption, political injustice and racial discrimination in his country. 
As such, Kee's political plays are usually defined as wholly "Malaysian”. With a more distinct and authentic Malaysian flavour, Kee evokes his conjured brand of humour and a version of narration which I like to term as "Kee-ism". It is narration in dramatic form that draws its strength from a satirical and parodical style and from absurdist and existentialist elements borrowed from Brecht and Beckett ${ }^{\mathrm{ii}}$ which makes Kee's plays powerful tools in his own manner, method and style.

Kee's 1984 Here and Now is a political satire on Malaysia in which he draws inspiration from Orwell's 1984 and shows the hegemony of Big Brother being fought against by Wiran, a journalist and his girlfriend Yone. The play also focuses on this interracial relationship that is juxtaposed to the larger political tensions of the state. The play then narrates their challenges and difficulties as they navigate the difficult terrain of racial politics perpetuated by Big Brother.

The Big Purge is similar to 1984 Here and Now but instead of Big Brother, we have an evil Chief Minister (who spends a lot of time in the bathroom) and his diabolical politicians who rule over Equaland with an iron fist. The play details the social and political hurdles faced by the protagonist Rong and his like-minded friends as they contest the chaos and fear perpetuated by the Chief Minister.

Kee's third political play, We Could **** you, Mr. Birch, is first and foremost a 'historical' play that has 'futuristic' elements. It is Kee's retelling of the events leading to the assassination of J.W.W. Birch, the first British Resident (advisor) of Perak. The play has multiple plots ranging from Mastura's (the daughter of Maharajalela) fight for freedom from the shackles of the patriarchal system, to Kuntum, the slave who escapes from bondage and has an affair with Birch and a host of modern characters from the future who travel back to the past. The resulting collision of values provide for a moralistic ending by the playwright. 
Southeast Asian Review of English, 52.1(2014/2015): 122-138.

All of Kee's play are allegorical and political in nature. They are about Malaysia and Malaysian politics. His plays explore the actions in a narrative and are linked with the meanings that lie outside the narrative itself. In allegory, as defined in the Oxford Dictionary of Literary Terms, "the underlying meaning has moral, social, religious, or political significance, and characters are often personifications of abstract ideas." By adapting Orwell's "narrative of class rule, racial inequality and hegemonic construction of nationhood" (255), Kee povides a political critique of such issues that he felt, were very important to him.

\section{The Gamelan, Serunai, and Wayang Kulit in 1984 Here and Now}

In 1984 Here and Now, the figure of Big Brother is always televised and accompanied by traditional Malay music known as "Gamelan",iii that is played in the background. Jacqueline Lo in Staging Nation has observed that the use of such instruments is to "foreground Malay hegemony in state administration" (90) and this is also seen in the portrayal of Inner Party members as shadowy figures behind the screen in the form of traditional Malay puppeteering or "wayang kulit." iv

By appropriating the traditional form to depict the workings of the Inner Party, the production makes a strong statement about the use of tradition to perpetuate Malay political and cultural dominance... The wayang performance gave the impression of a shadowy realm where manipulation took place and conjured an ambience different from that of the common people. (Lo, 92)

Such traditional Malay instruments are an accompaniment to the "wayang kulit" performance. The wayang kulit thus adds a mythical and mystical element to Big Brother and his total control over the state. A daily televised version of him is an example of a projection of power that surpasses the traditional and the modern. The televised image of Big Brother shows how power and influence transgress the medium of its dissemination or propagation and exerts psychological control over the minds of its directed audience. 
Southeast Asian Review of English, 52.1(2014/2015): 122-138.

Big Brother's constant televised messages encroach and impinge upon the lives of the people while maintaining an aura of authority, reverence, fear, and God-like stature. By not appearing in person, he achieves a level of invincibility and detachment that is further strengthened by his control and repeated appearance on television. The character of Big Brother is a symbol of state power with total control over the visual media, a conventional but effective form of media that autocratic governments would like to have ownership over for their state propaganda. ${ }^{v}$ It is a most effective medium to disseminate information, and for the state to control this media apparatus, a certain ideological system should be in place, as observed by Lo:

The foregrounding of the role of visual media in a country that still has a high rate of illiteracy points to a more sophisticated critique of information networks and their dissemination of state propaganda. Historically, the media had been a powerful institution for mobilizing support for the dominant ideology, as shown in the opening video depicting the Kloots ${ }^{\mathrm{vi}}$ as the national enemy. (2004: 91)

\section{The Dalang - The Big Purge}

In The Big Purge, Kee introduces the audience to an actor who takes on the role of a "dalang" or a puppeteer. He in turn controls five characters in the "wayang" or play. Kee's presentation of the dalang ${ }^{\mathrm{vii}}$ as an all-powerful figure who controls his characters (the politicians) who eventually manipulates the events in Equaland and the lives of the people in the second performance hints at the multi-layered production interwoven into the storyline.

Seen from a multi-layered angle, while Kee stages his original play, the storyline depicts the dalang who "directs" another group of performers (the puppets or politicians like the Chief Minister, Minister Without Portfolio, Minister of Information, Minister of Education and the Minister of Home Affairs) and they in turn manipulate the events in Equaland.

TNEH 125 
Southeast Asian Review of English, 52.1(2014/2015): 122-138.

This play-within-a play, with the live audience watching it and the dalang controlling the events at Equaland is Kee's way of subverting (and juxtaposing) the traditional concept of a puppet show that "deliberately transgresses and subverts the usual protocols that observe the boundary between the genre of play as textual production and commentary as interventionist socio-political production" (Lim, 2003: 10). This is one key unconventional strategy that Kee employs as part of his resistance to more traditional methods of narration.

The portrayal and role of the dalang in The Big Purge clearly marks a shift from the conventional to the unconventional. Shirley Lim's analysis speaks of the characters controlled by the puppeteer as a "conceptualisation of Malaysian realpolitik and realisations"; they do not represent actual individuals or politicians but they signify "the workings of good and evil and of state mastery in a culture-specific teleology" (10-11). In the example below we see how the dalang maintains and propagates control and direction of the characters in Equaland.

(ACTOR PLAYING DALANG goes behind Wayang Kulit screen. Music strikes up.)

DALANG: In the kingdom of Equaland, The Chief Minister is king.

(He brings on the CHIEF MINISTER puppet.)

That is parliamentary democracy. Oooeeeyy!

(The percussion punctuates parts of the following.)

The Chief Minister is a genius. He has been chief Minister

And head of the ruling Equaland Equa Party,

For donkey's years.

He knows how to handle the ECP

--the Equaland Chingchong Party--

and he's got no problem with the EIP

--the Equaland Inayah Party.

He can put them in his pocket and they also

won't know.

Some more, they dare noy say anything against him.

Even if they don't agree with him, 
Southeast Asian Review of English, 52.1(2014/2015): 122-138.

they'll say, “OK, Sran Ti, you're right, Sran Ti."

Now the Chief Minister is in his office toilet, Sitting on his potty and talking to himself.

"What to do?" he is asking himself.

"What to do about those people who have been criticising the Government?

Want to know whether the people's money

is going into the right pocket.

Left-pocket cannot meh?

And then that so-called reform group

H.O.P.E.:

they want to question the Equaland

Economic Policy and the Constitution,

make fuss about people who are not

qualified getting promoted... (Kee, 2004b: 23-24)

Thus, the role of the dalang in the play is significant as the dalang is the master storyteller who creates the structures of a feudalistic political system and the "characters" that represent that system are merely representations of a political system based on the binary oppositions of good and evil. Lim concludes that Kee's choice of the dalang as the master storyteller/narrator then displaces the playwright as "first producer of the play's meaning" (Lim, 11) rather than emphasizing on the authority of the creator/playwright in the traditional context.

This approach by Kee seeks to subvert the conventionalities of traditional drama of the British canonical pretext. The dalang, who emasculates the creative prowess of the original playwright also empowers him (Kee) at the same time by transferring the context and meaning of the play to the authority of a Malay traditional wayang while validating its role in the production of meaning, in this context, the socio-economic and socio-political landscape of a nation. Prominence is, therefore, given to dalang and his ways of dictating the overall message of the play. While this would also make Kee appear to be impartial in his depiction of the content of the play since his role has been relegated, the thrust of the role of the dalang goes beyond the usual literal and metaphorical interpretation, to that of a storyteller and 
Southeast Asian Review of English, 52.1(2014/2015): 122-138.

manipulator who has reclaimed his part in the national affairs of the state regardless of affiliation.

Kee's inclusion of humour in this excerpt is a method to provoke the audience to consider the severity of the issue, and the debased actions of those in political power. Here the intense political manoeuvrings of the Chief Minister is done while he 'alone', at the 'throne' (euphemism for the toilet). His monologue reveals his true intentions that also include a personal vendetta against his political opponents.

\section{The Tiger Dance /Lion Dance in 1984 Here and Now}

Kee's use of parody 1984 Here and Now is seen when a multiracial crowd performs a tiger dance but is disrupted by a policeman because of permit issues. In that scene,

(. . . a group of Proles enter, watching a tiger dance being performed. Then a POLICEMAN comes by, blowing his whistle. The PROLES ignore him at first.) POLICEMAN: Stop! Stop!

(The dance comes to a stop.)

POLICEMAN: Do you have a permit for doing this?

(The performers look at each other, then one speaks up.)

PERFORMER: No.

POLICEMAN: You know you can't do this without a permit, don't you?

PERFORMER: Wy you all wan to make it hard for us? Wy mus take permit one?

POLICEMAN: Don’t argue. Stop this at once and go home. (Kee, 2004a: 27-28)

The group protests at first but later disbands reluctantly. Kee's example, which is a

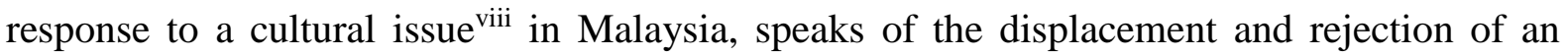
immigrant culture despite the efforts being done by the community to integrate with the 
Southeast Asian Review of English, 52.1(2014/2015): 122-138.

National Culture of Malaysia. Lo comments that this is a parody by Kee to show the difficulties faced by "immigrant" cultures to develop an organic bond with the country. Thus, "such symbolic offers of reconciliation are rejected by the authorities that break up the dance and quell the dancers' demands for 'a truly united nation'” (90). Kee's scene also highlights the dissatisfaction of the minority races toward the state for its uncompromising stand on the cultural elements that can or cannot be included as part of the national culture. Clearly, the grand cultural narrative of the nation has excluded the immigrant narratives of the minority races, and the exclusive power to determine this construct is itself an ideological strategy of the state. Thus Kee's 'parody' which is based on a real cultural issue in Malaysia speaks of this marginalisation, and exclusion from the nation's official narration.

\section{The Mahjong Game - 1984 Here and Now}

Kee's 1984 Here and Now, captures the ingenious use of Malaysian English or "Manglish" in the play as the language of the Proles/non-Malays. By focusing exclusively on the Proles, Kee is bringing the audience closer in their association to the political landscape of Malaysia while giving an intimate view of issues clearly affecting his own ethnic community and the other minority races affected by the discriminatory policies of the state. Perhaps this is why Kee has created the Proles to be in the likeness of the Chinese-Malaysian community from a social and cultural perspective. While the Proles speak in Manglish, which is dominated with Chinese nuances, the Party members speak in Standard English that is representative of Bahasa Malaysia. This language dichotomy indirectly forces the audience to confront the issue of "cultural superiority" and "racial essentialism" (Lo, 2004: 87) by such a switch of language command. The Standard English that is spoken by the Party members is thus associated with colonial hegemony and by showing how the Proles/non-Malays speak 
Southeast Asian Review of English, 52.1(2014/2015): 122-138.

Pidgin English, the language (Manglish) is a form of contestation of the use of Bahasa Malaysia as the dominant national language. Here Kee portrays Malay political and cultural dominance and subverts it with a colloquial language that is synonymous with the collective Chinese Malaysian identity.

In the play, Kee demonstrates a deep understanding and knowledge for the "colourful spectrum of Malaysian English" (Gilbert and Lo,11) that he uses comprehensively with strong doses of crude humour and wit. This is demonstrative of his understanding of the idiosyncrasies of Malaysian life that he pinpoints with accuracy and such observation is often at humorous intersections of common everyday activities of the Proles.

PLAYER 1: Dam bad luck laa. Never get der card I wan Mus chane place la.

PLAYER 2: Wy you worry? Nex game, der wind will blow Your way laa.

PLAYER 1: Wind from your backside la, like der Party.

PLAYER 3: Haiya, doan tok about der Party now la.

PLAYER 4: Ya, bring more bad luck only. Look at my card, all split.

PLAYER 2: Like our Prole party lah. Weak like anything. Everything Big Broder say, OK. Like balls shaking in der pants, man. And now, quarrelling some more, der leaders. Wan more power, wan top post. Firs, dey should be more strong to bring our problem to Big Broder. Instead, every time big Prole party meeting, big quarrel. Trow chair some more. No shame la, dese people. Meanwhile, our people suffer. Our chiren carn get place in university. Every year, only so many people can go in. Not fair la. Ay, ay, wait, wait! I wan der card. Doan lah play so fas! (Kee, 2004a: 28)

Kee's power of observation of Malaysian life, though humorous, is interlaced with snippets of dissatisfaction, frustration, and anger. What can be termed as "coffee shop talk", or personal ramblings by the Proles/non-Malays are in fact grouses by the people on state politics, federal policies on education, and socio-political commentaries that are topped with elements of superstition like not changing seats or mentioning negative/unlucky words ("the 
Southeast Asian Review of English, 52.1(2014/2015): 122-138.

Party") during a mahjong game. Comments like the weakness of Prole parties as compared to the dominant and powerful Big Brother, shows the disparity in positions and political clout, the lack of unity and the inability of the Prole party to highlight serious issues affecting the community are additional issues while the dictatorial qualities of Big Brother are alluded to. A serious contentious issue exposed in this short banter between Proles is the issue of equality among citizens and the limited number of university places for the Proles, with meritocracy and education being a recurring theme in the conversations among Proles. While Kee uses the Malaysian colloquial language ${ }^{\mathrm{ix}}$ to contest the national language (as explained earlier in this section), the use of "la", "can", "wan" has not undermined the serious underlying message of the conversation, one that Kee has strategically infused with the frustrations of the common people as a form of social commentary of mainstream events directed at the political state.

Kee's depiction of the "mah-jong" game portrays the inability of the Proles to do anything else but to talk. This 'coffee shop' talk over a traditional Chinese game describes the limitations of the ordinary citizens whose sphere of power is confined to the physical boundaries of the "mah-jong table, its tiles distract the player while the subject of their communication is divided between winning the game and a discourse on national politics, with the former gaining priority.

\section{The Pantun-The Big Purge}

In The Big Purge we see the use of the traditional Malay poetry or 'pantun.' In this scene, Mawiza and Runid take turns to recite a four-line pantun and they share a pantun at the end. In a move to perhaps capture the love between the couple, Kee turns to the traditional Malay 
pantun to portray the intimate love and courtship between the couple even as the prying eyes of religious authorities of the hegemonic state monitor their movements.

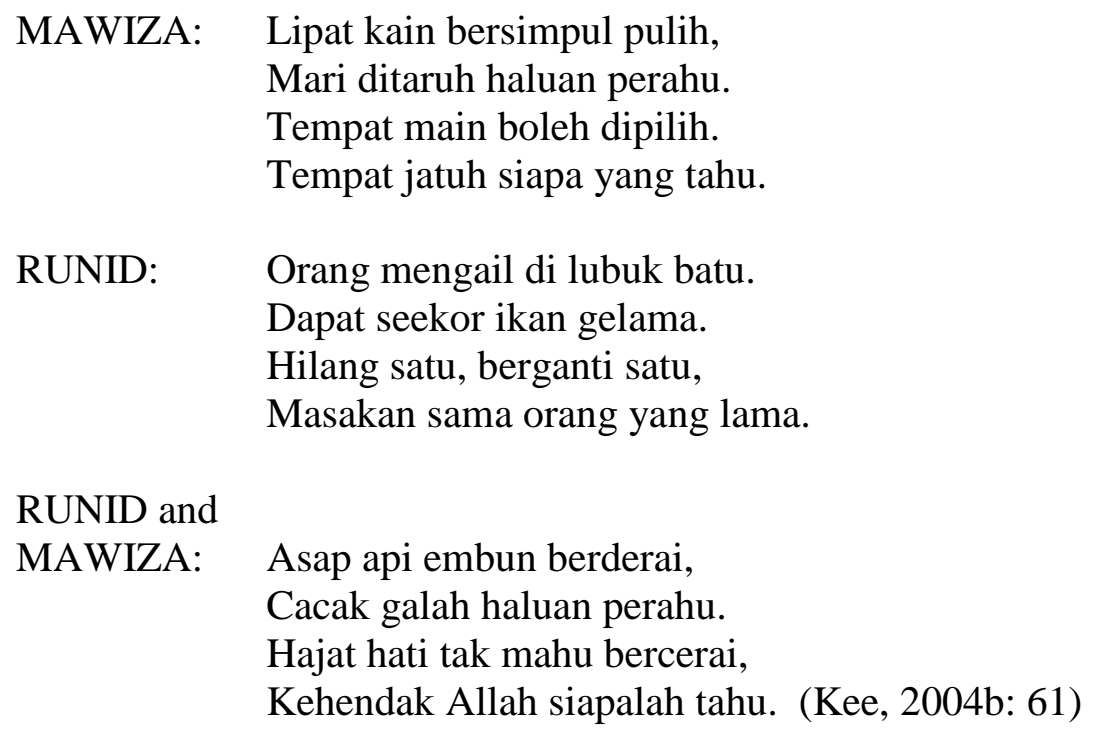

This highlights once again the moral dilemma and concerns faced by Malay couples as they struggle to live in a society that strictly regulates the moral code of conduct of its people.

The traditional form of poetry while invoking a poetic form of communication between the couple, is contrasted to the crude political language of the Chief Minister whose debased self-interest is evident in his personal revelations. Amidst the chaos and political uncertainty of the country, the pantun captures that subtle moment of personal human expression between Mawiza and Runid, in a form that reflects the feelings and emotions of individuals, away from the drudgery of race and religion perpetuated by the state.

\section{The Congkak Game - We Could **** You, Mr. Birch}

In the first introductory scene, Mastura is seen playing the Malay traditional game of "congkak" with her father Datuk Maharalela. Mastura's mastery of the family game sees her beating her father three times in a row, signifying her intelligence and quick thinking. In a way, perhaps it is also suggested that the game is too easy for her level of intellect and as her 
Southeast Asian Review of English, 52.1(2014/2015): 122-138.

father finds the game more difficult to play, his praises for her is negated tactically by Mastura who cleverly placates her father. Her sharp mind and clever psychological play with words are evident in the following banter.

LELA: Ah, this is the third time you have beaten me today, Mastura. You are getting to be too quick for your father.

MASTURA: You should not think you were beaten, Bapak ${ }^{\mathrm{xi}}$. Because you taught me the game, each time I win, you surpass yourself.

LELA: You have even required a quick tongue. I hope the man you someday marry will be deserving. (Kee, 2004c: 30)

As respectful as Mastura is in her replies to her father, the last line sets the tone for future disagreements between Datuk Maharajalela and his daughter. Her father's view is that her future and fate will be safeguarded if he could marry her off to a man, and that it is by marriage itself that a female could be worthy of a place in society which is the norm in most patriarchal/feudalistic societies. Mastura naturally objects to this proposition but her objections to being married and solely fulfilling the needs of her husband and her questioning of why women are not allowed to travel and explore foreign lands seem to fall on deaf ears. Denial to "fulfill" her life's experiences and to be ignorant of other worldly matters seem unacceptable to the logical thinking Mastura who is even more baffled that woman cannot be elected as village chiefs, a notion that her father finds hardly worth entertaining and at the same time, amusing.

Mastura's queries on culture and custom which is clearly against the grain, seems to provide a platform for the probing and questioning line of Kee, whose portrayal of Mastura challenges societal norms of gender, patriarchal values of society and the power to define, all of which are associated to the universal concept of power. Here Kee shows a negotiation and questioning of gender roles, one that is intimate in nature, between a daughter and her single father within the confines of a small family unit. This is indeed a strategic move by Kee to 
Southeast Asian Review of English, 52.1(2014/2015): 122-138.

foreground family affairs in the midst of a homely "congkak" game while still pointing to the intensity and importance of political upheaval in the background.

In a deeper analysis, Mastura's character questions and challenges her destiny and she symbolises change and apprehension to the traditional way of thinking, a subtle idea that Kee is proposing to the audience so that they will be critical and politically aware of issues affecting Malaysia. Mastura's character is a symbol of resistance; she can be contrasted with men who are supposed to be gate keepers of tradition, knowledge and wisdom but in reality they lack reason. In a subsequent scene that sees her serving tea to her father, she questions her father on matters pertaining to tradition and the "traditional" way of life such as the dignity of owning slaves which contradicts the notion of equality among individuals but Datuk Maharajalela finds her probing a little too direct and silences her with a slap because her enquiries are deemed to be "too direct" and that "There are things that cannot be questioned" (Kee, 2004c: 58). Caught in a bind over her logic, he expresses his regret to have "let a female learn so much" (ibid). Her father's justification is that everything must always fall into a certain structure to enable stability and order, and this includes slaves who run away from their masters who must be dealt with severely because they have broken the societal rules imposed on them. The highlighted conversation below demonstrates her father's dismissive nature who surmises how "order" is paramount at all times for uniformity and conformity.

MASTURA: But why must some men have masters? In the eyes of God, are we all not equal?

LELA: Mastura, your speech is too direct. That is not what we are used to.

MASTURA: Would not a slave seek to be equal and escape to a life of freedom?

LELA: Enough of this foolish talk!

MASTURA: If they run away, must they be tracked down like animals? 
Southeast Asian Review of English, 52.1(2014/2015): 122-138.

LELA: (Slaps her.) Enough! I did not bring you up so you can talk back to me! (Pause.) Yes, if they run away, they are behaving like animals and must be tracked down. They are disrupting order. Without order, we will be less than human. (58-59)

Mastura is challenging tradition and gendered roles because she believes tradition is not rigid, stoic and static and perhaps Kee is doing precisely the same thing. Kee's Birch is therefore challenging the hegemony of state sanctioned history and fixed notions of historical facts that are determined by historians in the way that he knows best, on stage and in the form of a play that he hopes will enlighten, entertain and generate a discourse on history, the concept of power, human relationships and morality. In a way, the play Birch then becomes a social statement and critical commentary by the dramatist on social issues affecting the Malaysian psyche from a socio-political and a socio-economic perspective.

\section{Conclusion}

As a conclusion, the traditional and cultural representations of such games portray the complex structure of meaning and symbolism associated with such recreational pastimes common in Malaysia. Such representations are a reflection of a dialogic space associated with the social activities and reflect an underlying discourse that is meant to dismantle the hegemony of the state and its influence on the individual.

From the use of such cultural and traditional arts/games, from Malay traditional instruments, the "wayang kulit", the role of the "dalang", mahjong, the lion dance, the pantun and the congkak, Kee's infusion of such cultural elements is his way of asserting his identity as a Malaysian playwright who has a deep and intimate interest in the Malaysian way of life. Such traditional/cultural games enable Kee to contest the political state through representations of people, society, and culture. These traditional games reflect the strength and unity of the people and have the ability to unite people. The games embody and 
Southeast Asian Review of English, 52.1(2014/2015): 122-138.

exemplify a united Malaysian way of life that is ideal in Kee's view. At the same time, Kee has used the multi-cultural/multi-racial activities as a united front as a critique against the extremism in Malaysian politics that threaten to destabilise the country that he truly loves and cherishes as a patriotic Malaysian. 
Southeast Asian Review of English, 52.1(2014/2015): 122-138.

\section{Works Cited}

Chomsky, Noam and Edward S. Herman, Manufacturing Consent: The Political Economy of the Mass Media. New York: Vintage, 1995.

Gilbert, Helen, and Lo, Jacqueline. Introduction. 1984 Here and Now. Singapore: Times Edition, 2004. Print.

Kee, Thuan Chye. Ask for No Bullshit, Get Some More! Malaysia: SIRD, 2013. Print.

---. 1984 Here and Now. Singapore: Times Editions, 2004a. Print

---. No More Bullshit, Please, We are all Malaysians. Marshall Cavendish International Asia, 2012.

---. The Election Bullshit. Malaysia: SIRD, 2013.

---. The Big Purge. Singapore: Times Editions, 2004b. Print.

---. We Could **** You, Mr. Birch. Singapore: Times Editions, 2004c. Print.

Lim, Shirley Geok-lin. “Abstracting the Nation in Kee Thuan Chye's 1984 Here and Now and The Big Purge: National Allegory or Modernist Theatre," Tamkang Review 29.2 (1998): 123. Print.

---. Introduction. The Big Purge by Kee Thuan Chye. Singapore: Times Books International, 2003. 5-20. Print.

Lo, Jacqueline. Staging Nation. English Language Theatre in Malaysia and Singapore. Hong Kong University Press: Hong Kong, 2004.Print.

Quayum, Mohammad A. and Wicks, Peter C. Editors. Malaysian Literature in English: A Critical Reader. Longman: Selangor, 2001.Print.

---.One Sky Many Horizons: Studies in Malaysian Literature in English. Shah Alam: Marshall Cavendish, 2007.Print.

Ten, Margaret. "Just When We Thought It Was Safe to Go the Theatre Again." In Kee Thuan Chye 1984 Here and Now. Petaling Jaya: K.Das Ink, 1985.Print.

\section{Notes}

\footnotetext{
${ }^{\mathrm{i}}$ Kee Thuan Chye was born in Penang on May 25, 954. Kee studied at Francis Light School and Penang Free School before graduating with a B.A. in English from the Science University of Malaysia ${ }^{i}$.Moving down to the capital city, Kee entered the journalism trade. He then completed his MA ${ }^{\mathrm{i}}$ in drama at the University of Essex in 1987 and is a well-known journalist, editor, actor, writer, and an occasional poet. Kee has worked with a number of major newspaper organisations in Malaysia such as The Straits Echo, New Straits Times,
} 
Business Times, New Sunday Times, and his last position was as an Associate Editor with The Star in 2009. Kee has written several books on Malaysian politics, the latest being, No More Bullshit, Please, We're all Malaysians, Ask for No Bullshit, Get Some More! and The Election Bullshit.

ii In an interview, Kee had said that he was also influenced by playwrights of the Theatre of the Absurd such as Pinter and Ionesco.

iii The term refers to a musical ensemble from Indonesia, especially the instruments.

iv 'Wayang Kulit' is a traditional cultural activity that is found predominately in the east coast of Peninsular Malaysia, namely the states of Kelantan and Terengganu.

'Noam Chomsky and Edward S. Herman's Manufacturing Consent discusses the role of the mass media in generating consensus for the ruling powers through the Propaganda Model.

${ }^{v i}$ In the play, the Kloots are depicted as Communist, in allegory to the communist insurgency in the Malayan Emergency from 1948-1960.

vii An interesting additional read would be "Malaysian Shadow Play Performance: Wayang Kulit Filled with Lights and Shadows", this short write-up focuses on Hamzah Awang Mat, a dalang from Kelantan and his troupe, the epic stories they perform as well as a detailed elaboration of all the traditional instruments used in a traditional shadow play troupe.

viii The then Home Minister Tan Sri Ghazali Shafie incensed the Chinese community by saying that the community should instead develop a "tiger" dance because there were no lions in Malaysia.

${ }^{i x}$ Malaysian colloquial English is also known as Manglish.

${ }^{\mathrm{x}}$ Congkak is a Malay traditional game ( a mancala game) which is played in many Southeast Asian countries in the region. Often played by girls, the objective of the game is for the opponent to capture more items (seeds, stones, or marbles) than your opponent.

${ }^{x i}$ A respectful term meaning "father" in the Malay language, it is usually spelt "Bapa" in its modern word form. 